\title{
Developmental Differences on Cognitive Inhibition in Children and Adults: Evidence from Vigilance Task
}

\author{
Manjunath Narra*, Beena Mathew, Sneha. M. V \\ Department of Speech Language Pathology and Audiology, Nitte Institute of Speech and Hearing, Mangalore, 575018, India
}

\begin{abstract}
The following study was carried out to know the developmental differences in cognitive inhibition between children and adults using auditory and visual vigilance tasks. A total of 62 Kannada - English bilingual speakers participated, divided into two groups. Test stimuli consisted of single digit numbers (1 to 9), presented randomly through headphones for the auditory vigilance task and visual presentation of the digits on a white screen for the visual vigilance task. Subjects were instructed to pay attention only to the target digit $\langle 6\rangle$, and to press the $\langle\mathrm{Y}\rangle$ key as quickly and accurately as possible. DmDx software was programmed to recognize this as the genuine response. The reaction time (RT) and accuracy rate were calculated in milliseconds and percentage respectively. Results revealed significant difference across age groups for RT and accuracy rate. The findings of the study indicated slower reaction time and reduced accuracy rate in younger children, supporting the hypothesis of cognitive inhibition.
\end{abstract}

Keywords Vigilance, Inhibition, Accuracy Rate

\section{Introduction}

Some of the executive functions like planning, inhibition, working memory and cognitive flexibility are responsible for guiding and controlling cognitive processes ([1][2]). Since the brain regions that mediate executive functions develop during life, it is important to take age into account in research studies. Performance on executive function tasks improves with age and becomes more pronounced during adolescence ([3]). Inhibition will be the subject of the present study, because there is no consistency in previous studies about those aspects of executive functioning. Inhibition is the ability to suppress the activation, processing, or expression of information that would otherwise interfere with the attainment of a behavioral or cognitive goal ([2],[4]). One such measure which is used to measure cognitive inhibition is by vigilance task. The efficiency of cognitive inhibition was hypothesized to change with age during childhood and hence lead to developmental changes on performance of neuropsychological test like vigilance ([5]).

Vigilance refers to the ability of an individual to maintain their focus of attention and to remain alert to stimuli over prolonged periods of time and is typically equated with sustained attention ([6]). Modern theories of attention ([7],[8],[9]) were able to explain the processes involved in

* Corresponding author:

man_n94@yahoo.com (Manjunath Narra)

Published online at http://journal.sapub.org/ijbcs

Copyright (C) 2012 Scientific \& Academic Publishing. All Rights Reserved vigilance. They recognized three important components that are essential for its execution viz. selection, vigilance and control. The selection component serves as a filter mechanism to process only the target or relevant information. Vigilance or sustained attention component describes the control of attention over time and is sometimes seen as an opponent process to selection that might be competing with selection for the same computational resources. Final component is the control, it allows for the allocation of computational resources according to the need of the experiment in different modality. These three components are viewed as part of the information processing that allows one to optimize reaction time to the appropriate target stimuli and therefore maximize accuracy rate of an individual.

The development of cognitive inhibition, as that of other executive functions in general, takes the shape of an inverse U-shaped curve with low performance in childhood, optimal performance in the adult period, and again low scores in the older age ([10]). Its development depends on the maturation of the frontal cortex ([11]). There are a lot of precursors of inhibition from the first year of life ([12]) and between 3-7 years, a marked progress of this function was observed. The performance of children in tasks that require remembering two rules and alternative responses according to different demands is often explained via inhibition. The efficiency of cognitive inhibition was hypothesized to change with age during childhood which leads to developmental differences in performance on neurophysiological tests like CPT and Vigilance. Reference[13] reported that cognitive inhibition in younger children showed less efficient processing because 
their limited working memory space was consumed with irrelevant information, mainly due to the immature cognitive inhibitory mechanism.

The inhibitory framework suggests that an efficient (fast $\&$ accurate) mental life requires the ability to limit activation to information most relevant to one's goal. Inhibition is likely to be inefficient in older adults, in very young children; and for people operating under conditions of fatigue, reduced motivation, or emotional stress or at a non-optimal point in their circardian arousal cycle ([14]). Three functions of inhibition proposed are: controlling access to attention's focus, deleting irrelevant information from attention and working memory, suppressing or restraining strong but inappropriate responses ([15]).

Various tests and softwares are addressed in literature to measure vigilance. The most commonly used is the continuous performance test (CPT). Reference[16] studied normative on 230 children (aged 3 to 7 years) for CPT on vigilance task. The study demonstrated a clear age development in capacity for vigilance task and no sex differences in normal children. The reason attributed for these developmental changes was the cognitive inhibition process. Reference[17] compared performance of children and adults on an interference suppression task and a response inhibition task, both known to require inhibition. Children were less accurate and had longer reaction times than adults on both tasks, and f-MRI data additionally revealed different loci of activation for children and adults.

In a review of 11 studies on age and vigilance, Reference[18] found that majority of the studies reported evidence of an age effect on hit rate (decrease with age), response time (increase with age) and false-alarm rate (increase with age). Reference[19] investigated 18 -year age changes on a 62 -min sensory vigilance task called the Mackworth Clock-Test. Target response time showed significant 18 year longitudinal age-related changes and significant cross-sectional age differences. Overall results of studies reported U-shaped function with a minimum at middle age for response time measures. Reference[5] has found evidence of developmental improvement over the elementary school years in the ability to inhibit the activation and retrieval of task-irrelevant information in a directed forgetting paradigm. These findings suggest that younger children experience difficulty inhibiting irrelevant or competing thoughts on various memory tasks.

The review of literature suggests an intricate relationship between cognitive inhibition and age and also the ability to measure it through vigilance task. The concept of inhibitory function plays a major role in understanding age-related differences in cognition. However, the extent and nature of age-related differences in vigilance task by different modalities (auditory and visual) in typically developing children and adults is not yet studied extensively. Therefore, the present study was designed to investigate potential developmental differences in cognitive inhibition measured using auditory and visual vigilance tasks across children and adults.

\section{Method}

\subsection{Subjects}

A total of 62 subjects were included in this study. They were divided into two groups consisting of 31 subjects in each group (15 boys and 16 girls). Group I consisted of children in the age range of 9 to 12 years (mean age 11 years) and group II consisted of young adults in the age range of 18 to 21 years. All the subjects were Kannada-English bilingual speakers. They were screened using WHO disability checklist ([20]) for any sensory, motor or cognitive impairments. The International Second Language Proficiency Rating Scale ([21]) was administered on all subjects individually to determine the language proficiency for reading, listening and speaking ability. The subjects across groups were also matched for their socio-economic status (upper middle to lower middle class) based on scale for measuring socio economic status ([22]).

\subsection{Instrumentation}

DmDx software installed in Compaq laptop, running on Microsoft windows XP professional connected with creative computer associates headphone was used to measure reaction time and accuracy of responses. The $\mathrm{DmDx}$ is a Win-32 based display system used in psychological laboratories to measure reaction times to visual and auditory stimuli ([23]).

\subsection{Procedure}

\subsubsection{Selection of stimuli}

Test stimuli consisted of single digit numbers from 1 to 9 . The target digit $\langle 6\rangle$ was selected randomly for which the subject was asked to respond to and which the software would recognize as a genuine response.

\subsubsection{Presentation of stimuli.}

Stimuli were presented in two experiments. Experiment I consisted of visual vigilance task, where digits were presented visually at the center of the computer screen on a white square. The numbers were presented randomly one by one at the centre of the square. Experiment II includes auditory vigilance task, in these digits were presented randomly through headphones. These digits were recorded digitally in female voice and digitized at $44 \mathrm{kHz}$ and scaled to an average intensity of $60 \mathrm{~dB}$. In this study, the target digit presentation criterion was set at $30 \%$, the presentation time of each stimuli was set at $500 \mathrm{msec}$ with interstimulus interval between digits was set at $1000 \mathrm{msec}$. The test continued for a duration of 10 minutes without interruption for both the experiments.

\subsubsection{Instruction}

Subjects were instructed to pay attention only to the target digit $<6>$ and to press the $<\mathrm{Y}>$ key as quickly and accurately as possible once he/she recognized the target digit.

\subsubsection{Test environment.}


Each subject was tested individually in a silent room with minimal background noise. They were seated $60 \mathrm{~cm}$ away from the computer monitor.

\subsubsection{Response}

Motor responses were selected for this study i.e., $<\mathrm{y}>$ key press for the correct target stimuli as early as possible from each subject. The results of the experiments were given by average recognition frequency of the target digit for the total duration. This measure is termed as accuracy rate or vigilance score, calculated by dividing the total number of recognized frequency by the total number of presented frequency and is represented in percentage (\%). Another measure which was included in the study was reaction time. It is the elapsed time between the presentation of stimuli and subsequent motor response such as pressing a key $<y>$ corresponding to a target digit, when it appears on the screen. The responses were recorded in milliseconds (msec). $\mathrm{DmDx}$ software measured both measures accurately.

\subsection{Statistical Analysis}

The obtained data were tabulated and subjected to statistical analysis using SPSS Version 17. Mean accuracy rate (\%) and mean reaction time $(\mathrm{msec})$ were calculated for each group. ANOVA was administered to note the statistical difference across groups for visual and auditory vigilance task.

\section{Results}

\subsection{Mean Accuracy rate}

Table 1 and Figure 1 show the mean accuracy rate for experiment I and II across groups. Results showed lower accuracy rates for children for both visual and auditory vigilance tasks. The mean accuracy rate for visual vigilance task in children was $63.17 \%$ and for adults it was $95.16 \%$. ANOVA was administered to find out whether the difference between the two was statistically significant. Results showed significant difference between groups[F $(1,60)=2486.46$, $\mathrm{p}<0.001]$. Similarly for auditory vigilance task, $59.52 \%$ was noted for children and $95.68 \%$ for adults. Significant difference was obtained across groups $[\mathrm{F}(1,60)=758.76$, $\mathrm{p}<0.001]$.

Table 1. Mean Accuracy Rate and Standard Deviation (SD) for Experiment I and II Across Groups. (VVT-Visual Vigilance Task; AVT-Auditory Vigilance Task)

\begin{tabular}{|c|c|c|c|}
\hline \multirow{2}{|c|}{$\begin{array}{c}\text { Mean Accuracy Rate } \\
(\%)\end{array}$} & $\begin{array}{c}\text { Experiment I } \\
(\mathrm{VVT})\end{array}$ & $\begin{array}{c}\text { Experiment II } \\
(\mathrm{AVT})\end{array}$ \\
\cline { 2 - 4 } & Mean (SD) & Mean (SD) \\
\hline \multirow{3}{*}{ Group I } & Boys & $63.00(1.78)$ & $60.36(2.94)$ \\
\cline { 2 - 4 } & Girls & $63.50(0.83)$ & $58.00(7.84)$ \\
\cline { 2 - 4 } & Overall & $63.17(1.50)$ & $59.52(5.10)$ \\
\hline \multirow{4}{*}{ Group II } & Boys & $96.30(3.36)$ & $94.74(6.99)$ \\
\cline { 2 - 4 } & Girls & $93.90(3.24)$ & $96.71(5.12)$ \\
\cline { 2 - 4 } & Overall & $95.16(3.45)$ & $95.68(6.11)$ \\
\hline
\end{tabular}

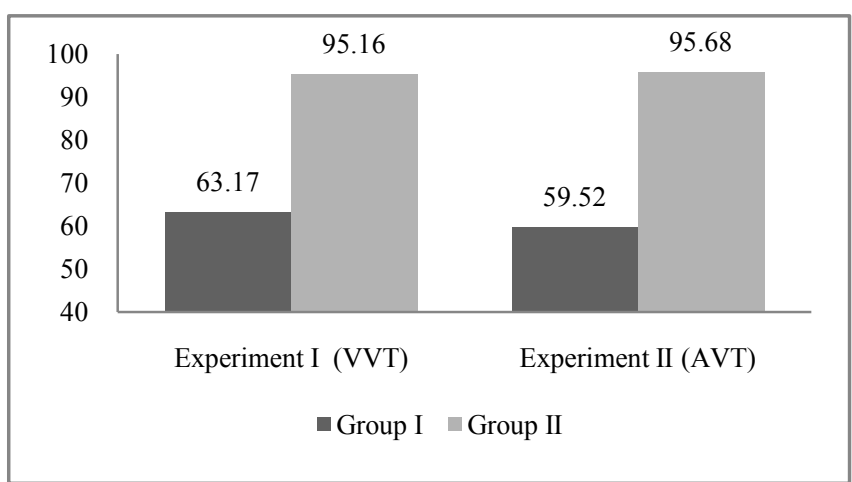

Figure 1. Mean accuracy rate (\%) for experiment I and II across groups.

\subsection{Mean Reaction time}

Table 2 and Figure 2 depict the mean reaction time for experiment I and II across groups. Results showed slower reaction time for children for both visual and auditory vigilance tasks. The mean reaction time for visual vigilance task in children was $524.39 \mathrm{msec}$ and for adults it was 474.31 msec. On treating the data with ANOVA, a statistical significant difference was obtained between groups[F $(1,46)=8.51, p<0.005]$. For auditory vigilance task, 678.98 msec was noted for children and $560.83 \mathrm{msec}$ for adults. Significant difference was obtained across groups[F $(1,50)=8.68, \mathrm{p}<0.005]$.

Table 2. Mean Reaction Time and Standard Deviation (SD) for Experiment I and II Across Groups. (VVT-Visual Vigilance Task; AVT-Auditory Vigilance Task)

\begin{tabular}{|c|c|c|c|}
\hline \multicolumn{2}{|c|}{$\begin{array}{c}\text { Mean Reaction } \\
\text { Time }(\mathrm{msec})\end{array}$} & $\begin{array}{c}\text { Experiment I } \\
(\mathrm{VVT})\end{array}$ & Experiment II (AVT) \\
\cline { 3 - 4 } \multicolumn{2}{|c|}{} & Mean (SD) & Mean (SD) \\
\hline \multirow{3}{*}{$\begin{array}{c}\text { Group } \\
\text { I }\end{array}$} & Boys & $510.17(33.30)$ & $688.20(69.52)$ \\
\cline { 2 - 4 } & Girls & $538.61(53.81)$ & $662.08(99.66)$ \\
\cline { 2 - 4 } & Overall & $524.39(48.50)$ & $678.98(84.59)$ \\
\hline \multirow{3}{*}{$\begin{array}{c}\text { Group } \\
\text { II }\end{array}$} & Boys & $493.74(91.71)$ & $560.85(79.96)$ \\
\cline { 2 - 4 } & Girls & $454.88(43.09)$ & $560.82(89.76)$ \\
\cline { 2 - 4 } & Overall & $474.31(72.65)$ & $560.83(82.60)$ \\
\hline
\end{tabular}

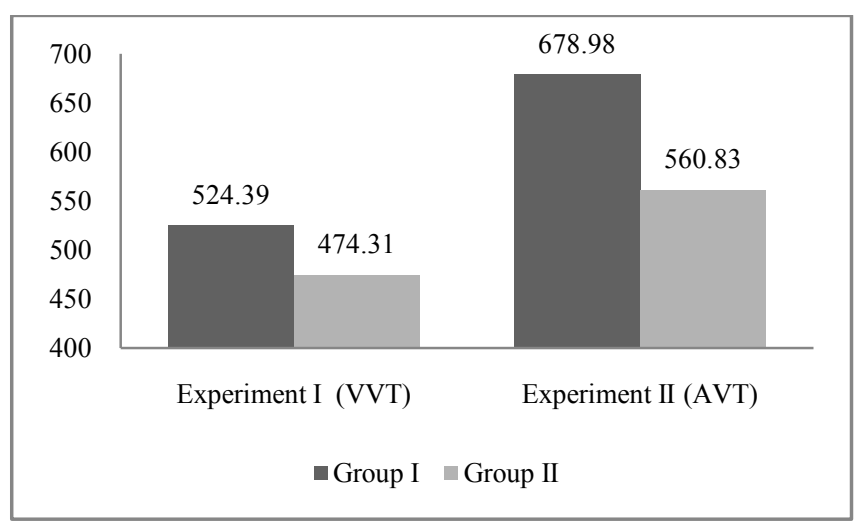

Figure 2. Mean reaction time (msec) for experiment I and II across groups.

\section{Discussion}

The aim of the present study was to note developmental differences in cognitive inhibition between children and 
adults for visual vigilance and auditory vigilance tasks. The data was analyzed for accurate rate and reaction time measurements. The results revealed that overall performance of adults from group II were better than children of group I for both measurements in visual and auditory vigilance tasks. Statistical significant difference was obtained for both the experiments across groups. As no gender differences were found with respect to vigilance task in children and adults ([16],[18][24-26]), data and statistics were presented for boys and girls combined.

The results are consistent with the findings of several earlier studies reporting lower accuracy scores in children compared to that of adults ([10],[13],[17],[18],[24]) despite the differences in the task variables used in these studies. These developmental differences between children and adults for vigilance tasks may be attributed to role of inhibition processes ([27],[28],[29]). The notion is that the suppression of irrelevant information (i.e., inhibition), coupled with the activation of relevant information. This idea of suppression and activation stems from the models of attention that emphasize dual processes that operate on attended and unattended information ([30],[31]). These models emphasize that vigilance is achieved by an excitatory mechanism that acts to enhance target information, complemented by an inhibitory mechanism that acts to suppress competing information. Also, efficient inhibitory processes contribute to improved memory performance in vigilance task across age ([29],[32]). However, inefficient inhibition model posits that young children are not able to suppress the activation of task-irrelevant information and associations efficiently during cognitive processing i.e., while target selection. Children's immature inhibitory mechanisms could result in less efficient cognitive processing because their limited working-memory space is consumed with irrelevant information. Hence a reduced accuracy rate was observed in children compared to that of adults, irrespective of modality ([33]).

The findings are consistent with studies which reported that reaction time is faster in adults compared to that of children ([17-19],[34-37]). The faster reaction time in adults may be attributed to increased speed of information processing and hence decreasing the time taken for digit retrieval as age increased. Reference[38] stated that not only the simple mechanical factors like the speed of nervous conduction contribute to these differences but also that the adults have a tendency to be more careful and monitor their responses more accurately and precisely. These speculations may also be considered as the reasons for slower reaction time with age in the present study. When troubled by a distraction, children tend to devote their exclusive attention to one stimulus, and ignore another stimulus, more completely than adults ([39])

The results of this study must be considered in the context of following limitations. The current investigation was performed for visual and auditory mode of vigilance task for children and adults only. The pattern of results indicated in this study may not hold true for other CPT versions with differing task parameters (stimuli type, stimuli quantity and inter stimulus interval). Also, since the factors that affect the vigilance performance were not controlled in the present study more precisely, further studies can be carried out in this regard. However, the clinician should be aware of the factors that affect the vigilance performance like reduced motivation, emotional stress, fatigue and a non-optimal in their circardian arousal cycle while data recording.

\section{Conclusions}

The current study investigated development of cognitive inhibition measured through vigilance task across modality in normal school going children and adults. Results clearly indicated reduced accuracy rate and slower reaction time in children, supporting the hypothesis of cognitive inhibition. The data from the present study gives a more comprehensive view of the sustained attention/vigilance skills in normal children. Studies can be carried out to address how sustained attention/vigilance and language acquisition are related in children and; how it facilitates for language development. Moreover, studies on cognitive inhibition can be undertaken to validate the clinical importance of vigilance as a tool in the standard test battery, to aid the diagnosis of various childhood language disorders.

\section{REFERENCES}

[1] Geurts H. M, Corbett B, Solomon M, "The paradox of cognitive flexibility in autism", Trends in Cognitive Sciences, vol. 13, pp. 74-82, 2009

[2] Van Zomeren E, Eling P, "Aandacht en executieve functies". In B. Deelamn P Eling, E De Haan, E Van Zomeren, "Klinische neuropsychologie", Amsterdam, 2006.

[3] Happé F, Booth R, Charlton R, Hughes C, "Executive function deficits in autism spectrum disorders and attention deficit/hyperactivity disorder: Examining profiles across domains and ages", Brain and Cognition, vol. 61, pp. 25-39, 2006.

[4] Christ S. E, Holt D. D, White D. A, Green L, "Inhibitory control in children with autism spectrum disorder", Journal of Autism and Developmental Disorders, vol. 37, pp. 1155-1165, 2007.

[5] Harnishfeger K. K, Pope R. S, "Intending to forget: The development of cognitive inhibition in directed forgetting", Journal of Experimental Psychology, vol. 62, pp. 292-315, 1996.

[6] Berardi A, Parasuraman R, Haxby J. V, "Overall vigilance and sustained attention decrements in healthy aging", Experimental Aging Research, vol. 27, pp. 19-39, 2001.

[7] Parasuraman R, The attentive brain, Mass: MIT Press, Cambridge, 1998.

[8] Parasuraman R, Davies D. R, Varieties of attention, Academic Press, New York, 1984.

[9] Posner M. I, Boies S. J, “Components of attention”, Psychological Review, vol.78, no. 5, pp. 391-408, 1971. 
[10] Zelazo P. D, Craik F. I. M, Booth L, "Executive function across the life span", Acta Psychologica, vol. 115, pp.167-183, 2004.

[11] Diamond A, Taylor C, "Development of an Aspect of Executive Control: Development of the Abilities to Remember What I Said and to "Do as I Say, Not as I Do", Developmental Psychobiology, vol. 29, no. 4, pp. 315-334, 1996.

[12] Benga O, "Dezvoltarea cogniției sociale la copii”, Doc. Thesis, Univ. of Bolyai, Romania, 2003.

[13] Bjorklund D, Harnishfeger K, "The resources construct in cognitive development: Diverse sources of evidence and a theory of inefficient inhibition", Developmental Review, vol. 10, pp. 48-71, 1990.

[14] Hasher L, Zacks R. T, May C. P, Inhibitory control, circadian arousal, and age in Attention and performance, MA: MIT Press, Cambridge, 1999.

[15] Lustig C, Hasher L, Zacks R, Inhibitory Deficit Theory: Recent Developments in a New View. World Composition Services. Sterling, 2007.

[16] Levy F, "The development of Sustained Attention (vigilance) and Inhibition in children: some normative data", Journal of Child Psychology and Psychiatry, vol. 21, pp. 77-84, 1980.

[17] Bunge S. A, Dudukovic N. M, Thomason M. E, Vaidya C. J, Gabrieli, J. D. E , "Immature frontal lobe contributions to cognitive control in children: Evidence from fMRI", Neuron, vol. 33 , pp. 301-311, 2002.

[18] Davies D. R, Parasuraman R, The psychology of vigilance, Academic Press, London, 1982.

[19] Giambra L. M, Quilter R, "Sustained attention in adulthood: A unique, large sample, longitudinal and multi cohort analysis using the Mackworth Clock-Test", Psychology and Aging, vol.3, pp. 75-83, 1988.

[20] Singhia P, Kumar M, Malhi P, Kumar R, "Utility of the WHO Ten Questions Screen for Disability Detection in a Rural Community-the North Indian Experience", Journal of Tropical Pediatrics, vol.53, no 6, pp. 383-387, 2007.

[21] Wylie E, Ingram D. E, International Second Language Proficiency Ratings (ISLPR) General proficiency version for English Nathan, 2006.

[22] Aggarwal O. P, Bhasin A. K, Chabra P, Aggarwal K, Rajoura O. P, "A new instrument (Scale) for measuring the socio economic status of a family: Preliminary study", Indian Journal of Community Medicine, vol. 30, no.4, pp.10-12, 2010.

[23] Jonathan C, DMDX software Version. 3.2.6.4[Computer Software], Department of Psychology, Univ of Arizona, 1993.

[24] Seidel W. T, Joschko M, "Evidence of difficulties in sustained attention in children with ADHD", Journal of Abnormal Child Psychology, vol. 18, pp. 217-229, 1990.

[25] Levy F, Hobbes G, "The influences of social class and gender on sustained attention (vigilance) and motor inhibition in children", Australian and New Zealand Journal of Psychiatry, vol. 13, pp. 231-234, 1979.
[26] Manjunath. N, Ganesh A. C, Vijay Kumar "Acquisition of Vigilance in Kannada-English speaking children: A pilot study", Journal of Indian Speech- Language-Hearing Association, vol. 25, no.2, pp. 90-97, 2011.

[27] Dagenbach D, Carr T. H, Inhibitory processes in attention, memory and language, Academic Press, San Diego, 1994.

[28] Dempster F. N, Brainerd C. J, Interference and inhibition in cognition, Academic Press, San Diego, 1995.

[29] Harnishfeger K. K, Bjorklund D. F, “A developmental perspective on individual differences in inhibition. Learning and Individual Differences”, vol. 6, pp. 331-355, 1994.

[30] Stadler M. A, Hogan M. E, "Varieties of positive and negative priming". Psychonomic Bulletin and Review, vol.3, pp. 510-514, 1996.

[31] Neumann E, DeSchepper B. G, "Costs and benefits of target activation and distractor inhibition in selective attention", Journal of Experimental Psychology: Learning, Memory, and Cognition, vol.17, pp. 1136-1145, 1991.

[32] Harnishfeger K. K, Bjorklund D. F, The ontogeny of inhibition mechanisms: A renewed approach to cognitive development, Cited in M. L. Howe \& R. Pasnak, Emerging themes in cognitive development: Vol. 1. Foundation, Springer-Verlag, New York, 1993.

[33] Hasher L, Zacks R. T, "Working memory, comprehension, and aging: A review and a new view". Cited in G. H. Bower, The psychology of learning and motivation, Academic Press, New York, 1988.

[34] Jevas S, Yan J. H, "The effect of aging on cognitive function: a preliminary quantitative review", Research Quarterly for Exercise and Sport, vol.72, pp. 49, 2001.

[35] Luchies C. W, Schiffman J, Richards L. G, Thompson M R, Bazuin D, De Young A. J, "Effects of age, step direction, and reaction condition on the ability to step quickly", The Journals of Gerontology, vol. 57, no. 4, pp. 246- 249, 2002.

[36] Hultsch D. F, MacDonald S. W, Dixon R. A, "Variability in reaction time performance of younger and older adults", The Journals of Gerontology, vol.57, no.2, pp. 101, 2002.

[37] Rose C. L, Murphy L. B, Schickedantz B, Tucci J, “The effects of event rate and signal probability on children's vigilance", Journal of Clinical and Experimental Neuropsychology, vol. 23, pp. 215-224, 2001.

[38] Welford, A. T, Choice reaction time: Basic concepts. Cited in A. T. Welford, Reaction Times, Academic Press, New York, 1980.

[39] Redfern M. S, Muller M, Jennings J. R, Furman J. M, “Attentional dynamics in postural control during perturbations in young and older adults", The Journals of Gerontology, v ol.57, no. 8, pp. 298, 2002. 